\title{
Resistência ao Glyphosate em Biótipos de Buva (Conyza spp.) Das Regióes Oeste e Sudoeste do Parana ${ }^{1}$
}

\author{
Resistance to Glyphosate in Conyza spp. Biotypes in Western and Southwestern Parana, Brazil
}

TREZZI, M.M. ${ }^{2}$, VIDAL, R.A. ${ }^{3}$, XAVIER, E..$^{4}$, ROSIN, D. ${ }^{4}$, BALBINOT JR., A.A. ${ }^{5}$ e PRATES, M.A. ${ }^{6}$

\begin{abstract}
RESUMO - A resistência ao glyphosate em biótipos de Conyza spp. em áreas de lavoura das regiões oeste e sudoeste do Paraná causa grandes dificuldades ao manejo e, consequentemente, problemas econômicos e ambientais. Este experimento objetivou determinar a existência de resistência ao herbicida glyphosate em biótipos de buva (Conyza spp.) suspeitos, coletados em lavouras das regiões oeste e sudoeste do Paraná, comparando-os com biótipos suscetiveis. O delineamento experimental utilizado foi inteiramente casualizado, em esquema fatorial $12 \times 8 \times 3$. Os fatores consistiram de 12 biótipos de buva, doses de glyphosate $\left(0,100,180,324,583,1.050,1.888\right.$ e $\left.3.345 \mathrm{~g} \mathrm{ha}^{-1}\right)$ e épocas de avaliação para a variável controle (7, 14 e 21 dias após a aplicação). Para as variáveis matéria verde e matéria seca, o esquema fatorial utilizado foi o $12 \mathrm{x} 8$. As variáveis avaliadas foram controle visual, matéria verde, matéria seca, $\mathrm{C}_{50}, \mathrm{GR}_{50}$ e fator de resistência. A dose de $3.345 \mathrm{~g}$ glyphosate ha ${ }^{-1}$ foi a que apresentou maior nivel de controle dos biótipos, porém o controle dos biótipos suspeitos não foi efetivo, necessitando de doses mais altas. Todos os biótipos de buva suspeitos de resistência ao glyphosate tiveram essa característica confirmada. Entretanto, constatou-se grande amplitude de fatores de resistência, o que caracteriza a variabilidade entre os biótipos resistentes. Essas informações poderão ser utilizadas no planejamento de estratégias de manejo das populações resistentes e na prevenção da ocorrência de novas áreas com buva resistente ao glyphosate.
\end{abstract}

Palavras-chave: resistência a herbicidas, fator de resistência, variabilidade genética.

\begin{abstract}
Glyphosate-resistant biotypes of Conyza spp. (hairy fleabane, horseweed) in crop areas in the western and southwestern regions of the state of Paraná, Brazil, cause great management, economic, and environmental problems. This experiment aimed to determine the existence of horseweed biotypes resistant to glyphosate in the suspected populations collected from farms in western and southwestern Parana, comparing them with susceptible biotypes. The experimental design was completely randomized in a factorial $12 \times 8 \times 3$. The factors consisted of twelve biotypes of horseweed, eight glyphosate doses $\left(0,100,180,324,583,1.050,1.888\right.$, and $\left.3.345 \mathrm{~g} \mathrm{ha}^{-1}\right)$ and three evaluation periods for the control (7, 14 and 21 days after application). For the fresh and dry matter variables, the factorial design used was $12 \times 8$. The variables evaluated were visual inspection, fresh and dry matter, $C_{50}, G R_{50}$ and resistance factor. The dose of $3.345 \mathrm{~g}$ glyphosate ha-1 presented the highest control levels of all biotypes, but the control of the suspected biotypes was not effective, requiring higher doses. All the horseweed biotypes suspected of resistance to glyphosate have confirmed this feature. However, a wide range of resistance factors was verified, characterizing the variability among the resistant biotypes. This information may be used for planning management strategies of resistant populations, as well as in preventing the occurrence of new areas infested with glyphosate-resistant horseweed.
\end{abstract}

Keywords: weed resistance, resistance factor,genetic variability.

Recebido para publicação em 18.1.2011 e aprovado em 19.7.2011.

2 Professor Associado, Curso de Agronomia, Universidade Tecnológica Federal do Paraná, Campus Pato Branco, Via do Conhecimento, km 01, Caixa Postal 571, 85503-390 Pato Branco-PR, <trezzi@utfpr.edu.br>; ${ }^{3}$ Professor Associado, Universidade Federal do Rio Grande do Sul, Porto Alegre-RS; ${ }^{4}$ Acadêmico do Curso de Agronomia da UTFPR; ${ }^{5}$ Pesquisador, EMBRAPA Soja, Londrina-PR; ${ }^{6}$ Engo-Agr $\stackrel{0}{\text {. }}$, Coopavel Cooperativa Agroindustrial Ltda. 


\section{INTRODUÇÃO}

A resistência aos herbicidas em populações de plantas daninhas é, atualmente, um dos principais problemas enfrentados pelo setor agrícola em nivel mundial. Em 1996 foi constatado o primeiro caso de biótipo resistente (R) aos herbicidas inibidores da EPSPs, na espécie Lolium rigidum, na Austrália (Pratley et al., 1996). Atualmente, existem 21 espécies com biótipos resistentes aos inibidores da EPSPs em todo o mundo, o que confere o registro de, em média, mais de uma espécie por ano (Heap, 2011). No Brasil, o primeiro biótipo com resistência a EPSPs foi detectado na espécie Lolium multiflorum, no ano de 2003 (Vargas et al., 2005), seguindo-se posteriormente biótipos de duas espécies de buva (Conyza bonariensis e C. canadensis) (Moreira et al., 2007; Vargas et al., 2007; Lamego \& Vidal, 2008); mais recentemente, resistência a esse mecanismo de ação também foi detectada em leiteira (Euphorbia heterophylla) (Vidal et al., 2007a) e capim-amargoso (Digitaria insularis) (Heap, 2011). Os biótipos de buva resistentes a esse herbicida foram constatados em áreas de fruticultura, em São Paulo, e em lavouras de soja transgênica, no Rio Grande do Sul. Até hoje, no mundo, foram registrados dez casos de C. bonariensis e 26 de C. canadensis resistentes ao glyphosate.

As espécies conhecidas como "buvas" destacam-se por infestarem áreas abandonadas (terrenos baldios e margens de estradas), pastagens, culturas perenes (citros e café) e lavouras anuais (algodão, milho, soja e trigo) (Thebaud \& Abbott, 1995). Infestações densas de buva são atribuídas às características ecofisiológicas dessas espécies, entre as quais se destaca a elevada produção de sementes. As áreas em que tem havido maiores problemas com buva no Brasil são as de milho safrinha e áreas em pousio, pois oportunizam a germinação e o estabelecimento das plântulas na ausência de competição com espécies que possuem elevadas taxas de crescimento no período de inverno/primavera, como os cereais cultivados nesse período do ano.

Atualmente, não estão documentados na literatura brasileira monitoramentos das populações de buva (Conyza spp.) R coletadas nas regiões sudoeste, oeste e noroeste do Estado do Paraná, que são importantes regiões produtoras de grãos. Os monitoramentos podem distinguir populações resistentes de problemas de controle de plantas daninhas devido a outras causas, como presença de condições climáticas inadequadas, uso de subdoses de herbicidas, estádio das plantas inadequado para aplicação do herbicida, etc.

A resistência a herbicidas é confirmada após comparar curvas de dose-resposta do herbicida de biótipos com suspeita de resistência com um biótipo suscetivel (S) (Ryan, 1970). A partir do ajuste das curvas de dose-resposta, podem-se calcular as doses responsáveis pela redução de $50 \%$ da variável dependente $\left(\mathrm{GR}_{50}\right)$ dos biótipos R e S, o que permite quantificar o nível de resistência (Seefeldt et al., 1995). Assim, no processo de investigação da resistência, é possivel determinar os fatores de resistência (FRs) das populações coletadas e, assim, determinar, para cada, caso se há resistência de baixo ou alto nivel (Vidal et al., 2007b; Gazziero et al., 2008).

Experimentos conduzidos por Vargas et al. (2007), Moreira et al. (2007) e Lamego \& Vidal (2008) demonstraram que o nivel de $360 \mathrm{~g}$ glyphosate ha ${ }^{-1}$ é discriminatório, ou seja, permite distinguir biótipo suscetivel de biótipos $\mathrm{R}$ de Conyza bonariensis $\mathrm{e}$ C. canadensis. Os fatores de resistência para a variável controle variaram entre 7 e 11 para C. canadensis (Moreira et al., 2007) e entre 10 e 15 (Moreira et al., 2007) e 2,4 (Lamego \& Vidal, 2008) para C. bonariensis. Salienta-se que a determinação do nível de resistência das populações suspeitas fundamenta as decisões sobre as estratégias preventivas e de controle destas e permite compreensão mais adequada da forma de evolução da resistência (Vidal et al., 2007b).

Os objetivos deste trabalho foram: confirmar a ocorrência de resistência ao glyphosate em biótipos de Conyza spp. suspeitos, coletados nas regiões oeste e sudoeste do Paraná; determinar os níveis de resistência nos biótipos suspeitos, por meio do cálculo dos fatores de resistência; e analisar a magnitude dos fatores de resistência obtidos, considerando os biótipos e as determinações efetuadas. 


\section{MATERIAL E MÉTODOS}

O experimento foi conduzido em laboratório e casa de vegetação no município de Pato Branco, na latitude de $26^{\circ} 07^{\prime}$ S e longitude de $52^{\circ} 41^{\prime} \mathrm{W}$. O clima, de acordo com a classificação de Köppen, é subtropical úmido com verão quente ( $\mathrm{Cfa})$.

Foram coletadas sementes de buva (Conyza spp.) em áreas de lavoura com suspeita de resistência ao glyphosate, nas regiões sudoeste e oeste do Paraná, nos municípios de Campo Bonito, Três Barras, Corbélia, Cascavel, Capanema e Santa Izabel do Oeste (Figura 1). Também foram coletadas sementes de biótipos em áreas que não sofreram pressão de seleção por glyphosate, nos municípios de Florianópolis, Pato Branco e São Paulo. As sementes de buva foram coletadas de um número aproximado de 20 plantas em cada lavoura, não sendo registrado o número exato especificamente para cada área.

Em fase preparatória, em câmara de crescimento tipo BOD, as sementes foram depositadas em bandejas contendo substrato tipo mineral. Após a semeadura, procedeu-se à irrigação diária, sendo a temperatura do ar mantida constante a $20{ }^{\circ} \mathrm{C}$, com fotoperíodo de 12 horas. Após aproximadamente 40 dias, as mudas foram transferidas para os vasos, em casa de vegetação.

Foram empregados vasos com capacidade para $12 \mathrm{dm}^{3}$, os quais foram preenchidos com solo identificado como Latossolo Vermelho distroférrico, textura argilosa, álico, fase floresta subtropical perenifólia (Bhering et al., 2008), previamente peneirado, para retirada de partículas grosseiras e torrões.

$\mathrm{O}$ experimento foi conduzido em delineamento inteiramente casualizado, com quatro repetições, sendo arranjado em fatorial $12 \times 8$, em que o primeiro fator representou os 12 biótipos testados (Campo Bonito, Três Barras 1, Três Barras 2, São Paulo, Florianópolis, Pato Branco, Corbélia, Cascavel 1, Cascavel 2, Cascave1 3, Capanema e Santa Izabel do oeste), e o segundo, as doses de glyphosate $(0,100,180,324,583,1.050,1.888 \mathrm{e}$ 3.345 g e.a. ha-1), em que se utilizou o produto comercial Zapp QI. Portanto, foram testados 96 tratamentos, resultantes da combinação de
12 biótipos e oito doses de glyphosate. Os herbicidas foram aplicados quando as plantas de buva possuíam quatro folhas expandidas, por meio de pulverizador a pressão constante de $\mathrm{CO}_{2}$, com bicos leque 11002 e volume de calda de $180 \mathrm{~L}^{\text {ha }}{ }^{1}$.

Aos 7, 14 e 21 dias após a aplicação (DAA), avaliou-se visualmente o controle exercido pelo glyphosate através de uma escala de avaliação, em que $0 \%$ representa a ausência de controle e $100 \%$ a morte das plantas (Frans et al., 1986). Aos 21 DAA, determinou-se a matéria verde (MV) imediatamente após a coleta das partes aéreas das plantas; posteriormente, determinou-se a matéria seca (MS), após secagem em estufa a $60{ }^{\circ} \mathrm{C}$.

Os dados foram submetidos à análise de variância, pelo teste $\mathrm{F}(\mathrm{P}<0,05)$. As regressões entre variáveis dependentes e as concentrações de herbicidas foram ajustadas através de modelos não lineares, empregando-se o modelo logístico de quatro parâmetros e, em caso de não haver ajuste a este modelo, priorizando-se, em ordem decrescente, o modelo logístico de três parâmetros e os sigmoidais, de quatro e três parâmetros. O ajuste aos modelos foi procedido com auxílio do aplicativo Sigmaplot 10.0. Os fatores de resistência (FRs) foram calculados por meio do quociente entre os parâmetros $\mathrm{I}_{50}$ dos biótipos suspeitos de resistência e o do biótipo que apresentou o menor $\mathrm{I}_{50}$.

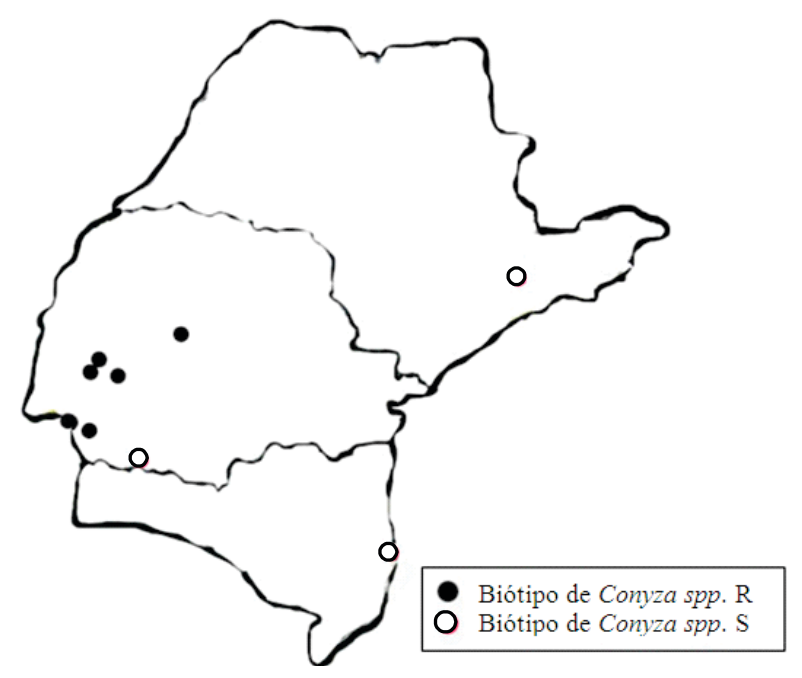

Figura 1 - Localização dos municípios em que foram efetuadas coletas de biótipos de Conyza spp. suspeitos de serem resistentes e suscetíveis ao glyphosate. 


\section{RESULTADOS E DISCUSSÃO}

Para a variável controle, matéria verde (MV) e matéria seca (MS), a análise da variância identificou interação significativa entre biótipo e dose de glyphosate.

Em geral, a elevação das doses de glyphosate resultou em aumento dos niveis de controle de todos os biótipos testados, com valores maiores para os biótipos de Conyza spp. $\mathrm{S}$ do que para os R. Houve aumento nos niveis de controle de todos os biótipos com o decorrer do tempo (Figura 2A, B, C).

Para a avaliação aos 7 DAA, o controle máximo ocorreu na maior dose testada, de 3.345 g e.a. ha ${ }^{-1}$, que equivale a 9,3 $\mathrm{L} \mathrm{ha}^{-1}$ de produto comercial genérico. Nessa condição, o nivel de controle dos biótipos oriundos de Florianópolis, São Paulo, Capanema e Pato Branco atingiu valores de 50,7, 49, 47,3 e 41\% em relação à testemunha, respectivamente. Na dose de $1.050 \mathrm{~g}$ glyphosate ha ${ }^{-1}$, os niveis de controle para os mesmos biótipos atingiram $39,50,18,3$ e $45 \%$ (Figura 2A).

Aos 14 DAA, os biótipos de Florianópolis, São Paulo e Pato Branco foram os que apresentaram os maiores niveis de controle com 1.050 g glyphosate ha-1: 99,3, 90 e 92,3\%, respectivamente, em relação à testemunha (Figura 2B). Aos 21 DAA, os niveis de controle para os mesmos biótipos foram de 100, 97 e 94\%, respectivamente (Figura 2C).

$\mathrm{Na}$ dose de $3.345 \mathrm{~g}_{\text {glyphosate ha }}{ }^{-1}$, os biótipos que apresentaram os menores niveis de controle na avaliação efetuada aos 7 DAA foram os de Campo Bonito e Três Barras 2, com 16 e $15 \%$, respectivamente. Para esses mesmos biótipos, quando foi utilizado glyphosate a $1.050 \mathrm{~g}$ ha ${ }^{1}$, os niveis de controle foram de 14 e $0 \%$, respectivamente (Figura $2 \mathrm{~A}$ ). Na avaliação efetuada aos 21 DAA, os níveis de controle de Campo Bonito e Três Barras 2, utilizando glyphosate a $3.345 \mathrm{~g} \mathrm{ha}^{-1}$, foram de 53,54 e 35\%, respectivamente, em relação à testemunha (Figura 2C).

Na média dos três períodos de avaliação, os biótipos oriundos de Corbélia, Cascavel 1, Cascave12, Cascave1 3, Capanema e Santa Izabel do Oeste apresentaram niveis de controle numericamente intermediários,
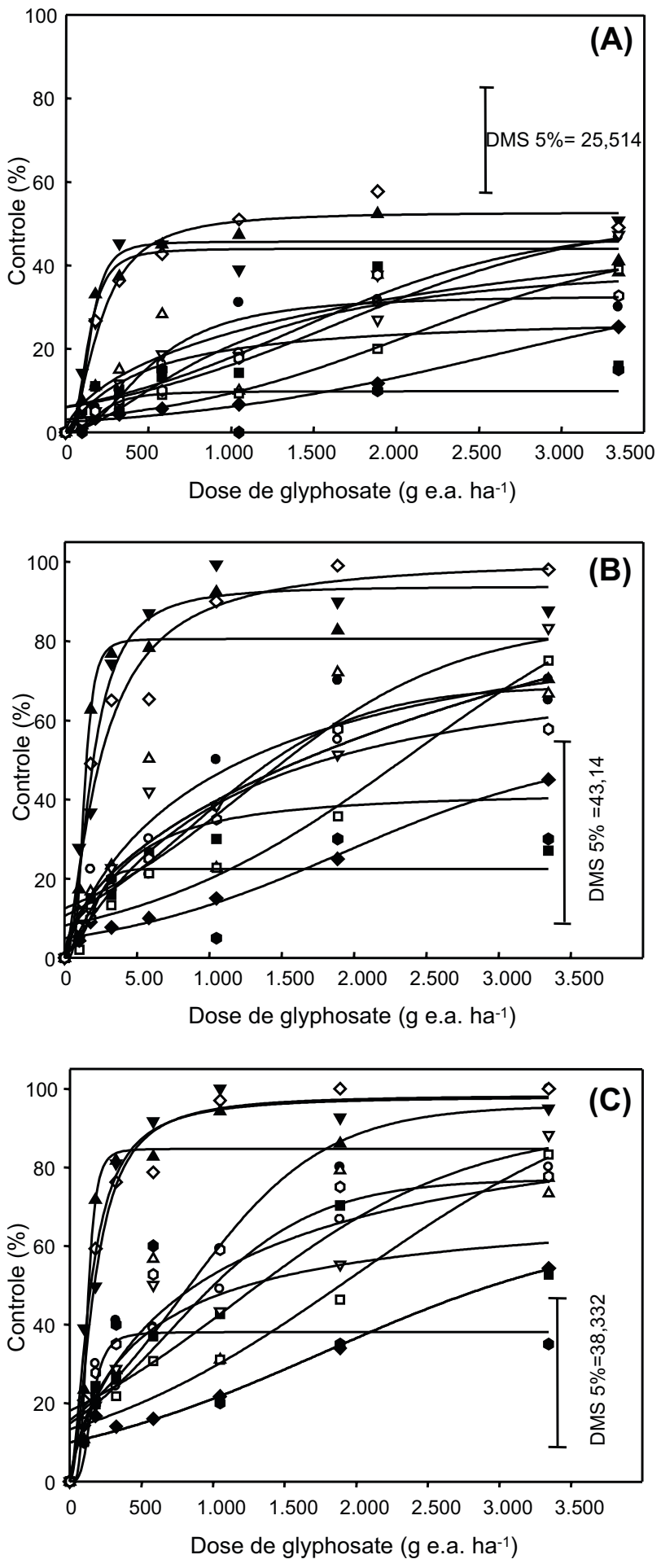

Figura 2 - Níveis de controle (\%) aos 7(a), 14(b) e 21(c) dias após aplicação (DAA) de biótipos de Conyza spp. (• Corbélia, $\triangle$ Cascavel 3, $\boldsymbol{\nabla}$ Florianópolis, $\triangle$ Cascavel 1, - Campo Bonito, $\square$ Cascavel 2, $\diamond$ Três Barras 1, $\diamond$ São Paulo, $\Delta$ Pato Branco, $\nabla$ Capanema, Três Barras 2, O Santa Izabel do Oeste), em função da aspersão com diferentes doses de glyphosate. 
situando-se entre os de Florianópolis, São Paulo, Pato Branco e os de Campo Bonito, Três Barras 1 e Três Barras 2 (Figura 2A, B, C). Isso demonstra que, mesmo utilizando doses de glyphosate da ordem de $3.345 \mathrm{~g} \mathrm{ha}^{-1}$ (9,3 $\mathrm{L} \mathrm{ha}^{-1}$ de produto comercial genérico), os niveis de controle dos biótipos Campo bonito, Três Barras 1 e Três Barras 2 foram insatisfatórios, ao passo que esse herbicida na dose de $1.050 \mathrm{~g} \mathrm{ha}^{-1}\left(2,9 \mathrm{~L} \mathrm{ha}^{1}\right.$ de produto comercial genérico) foi suficiente para produzir niveis de controle acima de $90 \%$ dos biótipos Florianópolis, São Paulo e Pato Branco.

Alguns autores estabeleceram escalas para classificação dos biótipos de Conyza canadensis com suspeita de resistência ao glyphosate, conforme o grau de insensibilidade ao herbicida. Na escala idealizada por Davis et al. (2008), as populações de campo com 0 a $60 \%$ de controle, estimadas visualmente, eram biótipos resistentes ao glyphosate; com 60 a $85 \%$ de controle, foram classificados como biótipos indeterminados; e com mais de $85 \%$ de controle, como biótipos suscetíveis ao glyphosate. Contudo, na escala de Main et al. (2004), quando as populações apresentaram $70 \%$ ou menor controle com aplicação da dose de $3.360 \mathrm{~g}$ glyphosate ha ${ }^{-1}$, os biótipos foram classificados como altamente R; os biótipos que apresentaram controle de $70 \%$ ou menos com aplicação de $840 \mathrm{~g} \mathrm{ha}^{-1}$ deste herbicida foram considerados R; e os biótipos S foram os que apresentaram acima de $75 \%$ de controle com esta última dose.

No presente experimento, analisando os controles obtidos dos biótipos testados aos 21 DAA (Figura 2C), o último período de avaliação, utilizando-se o critério proposto por Main et al. (2004), pode-se estabelecer a seguinte classificação dos 12 biótipos testados: os biótipos oriundos de Florianópolis, Pato Branco e São Paulo são classificados como S; os biótipos Campo Bonito, Três Barras 1 e Três Barras 2 são classificados como altamente $\mathrm{R}$; e os biótipos oriundos de Corbélia, Cascave1 3, Cascave1 1, Capanema e Santa Izabel do Oeste são classificados como R.

Relatos de baixos níveis de controle de Conyza spp. com aplicação de glyphosate foram feitos em trabalhos desenvolvidos no Brasil, porém testando apenas um ou poucos biótipos suspeitos de resistência. Vargas et al. (2007) verificaram que na dose de 720 g glyphosate ha ${ }^{-1}$ houve controle do biótipo $\mathrm{S}$ de $C$. bonariensis, mas que resultou em apenas $30 \%$ de controle do biótipo R. Similarmente, os biótipos resistentes ao glyphosate, quando aspergidos com o produto na dose de $720 \mathrm{~g} \mathrm{ha}^{-1}$, apresentaram controle inferior a $60 \%$ (Lamego \& Vidal, 2008) ou 30\% (Moreira et al., 2007), enquanto o biótipo $\mathrm{S}$ mostrou controle total. Nos Estados Unidos, plantas de biótipos de C. canadensis oriundos dos estados do Mississippi e Tennessee sobreviveram após aplicação de $840 \mathrm{~g}$ glyphosate ha ${ }^{-1}$, com redução de menos de $30 \%$ da matéria seca, na maioria dos casos (Koger et al., 2004).

Além da variabilidade genética inerente aos biótipos de Conyza, outros fatores, como a idade fisiológica das plantas e as condições de ambiente, poderiam influenciar os niveis de controle de Conyza spp.

Por exemplo, trabalhos realizados nos Estados Unidos indicaram que o estádio fisiológico das plantas de buva no momento da aplicação do glyphosate afetou o desempenho do produto (Shrestha et al., 2007). De fato, plantas de buva com oito ou menos folhas foram mais sensiveis ao glyphosate do que as plantas com 11 folhas, e, ainda, todas as plantas no estádio de cinco a oito folhas morreram com $3.300 \mathrm{~g}$ glyphosate ha-1. Em outro trabalho, biótipos de buva resistentes ao glyphosate, quando aspergidos no estádio de plântulas com 10 a $15 \mathrm{~cm}$ de estatura, somente foram controlados quando o herbicida foi utilizado na dose de $14.000 \mathrm{~g} \mathrm{ha}^{-1}$ (VanGessel et al., 2009).

Houve redução das matérias verde (MV) e seca (MS) de buva com o aumento das concentrações de glyphosate. Os biótipos que apresentaram maiores reduções de MV na maior dose testada (3.345 glyphosate ha-1) foram os de Corbélia, Capanema, Pato Branco, São Paulo e Florianópolis, com reduções da MV em relação à testemunha de 98, 100, 98, 98 e 97\%, respectivamente (Figura 3). Já os biótipos de Três Barras 2 e Campo Bonito apresentaram as menores reduções de MV na maior dose testada: apenas 33 e 19\%, respectivamente (Figura 3). Os demais biótipos avaliados apresentaram reduções de MV intermediárias entre os citados anteriormente. 


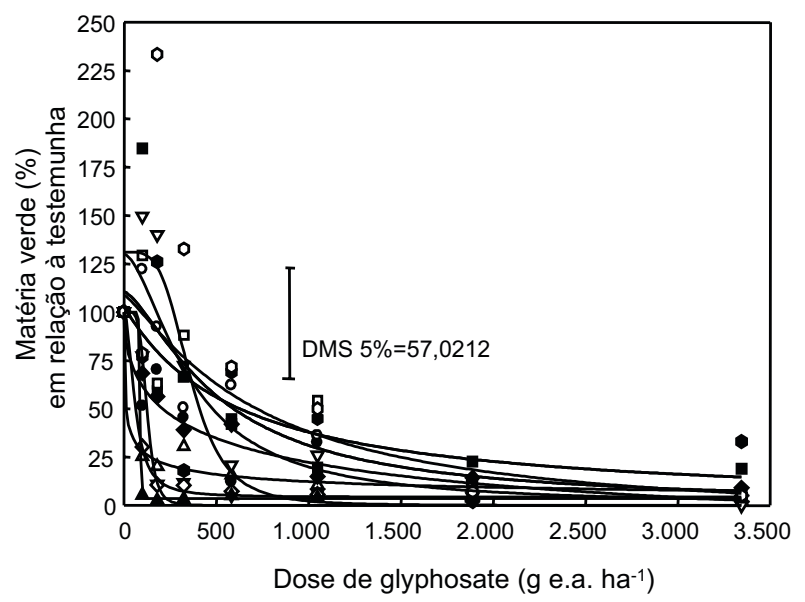

Figura 3 - Matéria verde dos biótipos de Conyza spp ( Corbélia, O Cascavel 3, $\mathbf{\nabla}$ Florianópolis, $\triangle$ Cascavel 1, - Campo Bonito, $\square$ Cascavel 2, $\diamond$ Três Barras 1, $\diamond$ São Paulo, $\Delta$ Pato Branco, $\nabla$ Capanema, Três Barras 2, O Santa Izabel do Oeste), em função da aspersão com diferentes doses de glyphosate.

Na avaliação da MS, houve comportamento semelhante ao da MV, pois se manteve a mesma ordem relativa de biótipos com elevada e baixa redução de biomassa das plantas de buva (Figura 4). Os biótipos de Campo Bonito e Três Barras 2 mantiveram porcentagens de MS em relação à testemunha de 83,6 e 56\% (Figura 4), respectivamente, mesmo com a utilização de $3.345 \mathrm{~g}$ glyphosate ha-1 $\left(9,3 \mathrm{~L} \mathrm{ha}^{-1}\right.$ da formulação genérica), comprovando a ineficiência desse herbicida em controlar as plantas dos biótipos R mesmo sob aplicações em estádios iniciais do desenvolvimento das plantas.

Os biótipos oriundos de Pato Branco e Florianópolis foram os que apresentaram os menores valores de $\mathrm{C}_{50}$ (niveis de herbicida necessários para produzir 50\% de controle) nos três períodos de avaliação, o que indica elevada suscetibilidade ao glyphosate. Os maiores valores de $\mathrm{C}_{50}$, registrados nos biótipos oriundos de Cascavel 2, Cascavel 1 e Três Barras 1, variaram entre 969 e $3.878 \mathrm{~g} \mathrm{ha}^{-1}$ de glyphosate (Tabela 1). Lamego \& Vidal (2008) verificaram que as doses de glyphosate necessárias para promover $50 \%$ de controle de C. canadensis $\left(\mathrm{C}_{50}\right)$ foram de 705 e $289 \mathrm{~g} \mathrm{ha}^{-1}$, para os biótipos $\mathrm{R}$ e $\mathrm{S}$, respectivamente.

O biótipo oriundo de Pato Branco atingiu os menores valores de $\mathrm{C}_{50}$ para a variável

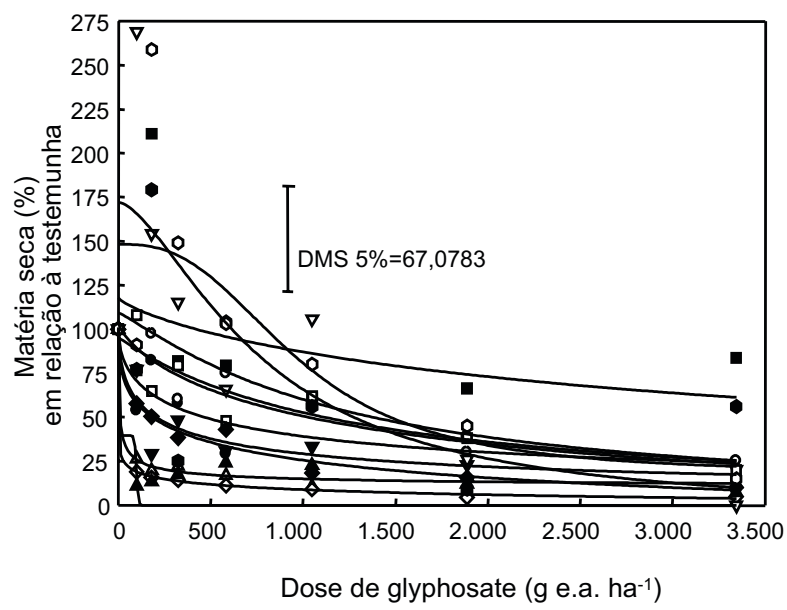

Figura 4 - Matéria seca dos biótipos de Conyza spp. (• Corbélia, ○ Cascavel 3, $\mathbf{\nabla}$ Florianópolis, $\triangle$ Cascavel 1, $\mathbf{C a m p o}$ Bonito, $\square$ Cascavel 2, $\diamond$ Três Barras 1, $\diamond$ São Paulo, $\boldsymbol{\Delta}$ Pato Branco, $\nabla$ Capanema, Três Barras 2, O Santa Izabel do Oeste), em função da aspersão com diferentes doses de glyphosate.

controle nos três períodos de avaliação (Tabela 1). Assim, ele foi selecionado com padrão de suscetibilidade para o cálculo dos fatores de resistência (FRs). Valores de FR superiores a 1,0 são indicativos de resistência. Como era esperado, os menores FRs para as variáveis controle, MV e MS foram encontrados nos biótipos São Paulo, Pato Branco e Florianópolis, ou seja, os biótipos coletados em áreas com ausência de pressão de seleção do herbicida (Tabela 1). Os maiores valores de FR para a variável controle situaram-se na faixa entre 14 e 18 e foram detectados nos biótipos Cascavel 2 e Três Barras 1.

Os maiores valores de FR para MV foram obtidos pelos biótipos Cascavel 2, Três Barras 2 e Santa Izabel do Oeste e foram compreendidos na faixa entre 6,9 e 8,3 . Para a MS, os maiores valores de FR foram obtidos pelos biótipos Campo Bonito e Cascavel 2, com 37,3 e 13,8, respectivamente (Tabela 1). Dessa forma, para as variáveis MV e MS, desconsiderando-se os biótipos Pato Branco, Florianópolis, São Paulo e Cascavel 1, todos os demais demonstraram resistência ao herbicida glyphosate.

Em experimentos conduzidos em outros locais do Brasil, foram calculados FRs para biótipos de buva. Para biótipos de C. canadensis resistentes ao glyphosate, Moreira et al. (2007) 
encontraram FRs da ordem de 10,8 e 7,1 para a variável controle e de 6,2 e 6,7 para a MS. Esses autores detectaram para a espécie C. bonariensis FRs de 14,75 e 10,40, para a variável controle, e de 5,02 e 1,52, para a variável MS. No experimento conduzido por Lamego \& Vidal (2008), para a variável controle os FRs foram de 2,3 e 2,4, para $C$. bonariensis e C. canadensis, respectivamente. Em análise efetuada em biótipos dos Estados Unidos, Vangessel et al. (2001) e Koger et al. (2004) detectaram valores de FR entre 8 e 13 e entre 8 e 12, respectivamente, para a variável MS.

$\mathrm{O}$ presente experimento detectou amplitude dos valores de FR nos biótipos superior à encontrada em trabalhos desenvolvidos no Brasil e no exterior, em razão provavelmente do maior número de biótipos avaliados e também devido a outros fatores, nominados a seguir.

Em primeiro lugar, os valores de FR poderiam variar em função de características genéticas dos biótipos testados. Nesse caso, deve-se considerar que a resistência ao glyphosate em buva é regulada por um gene dominante incompleto, único (alelo I), localizado no genoma nuclear (Halfhill et al., 2007). Assim, é possivel que as populações de plantas coletadas provavelmente ainda estejam segregando, o que por si só é uma fonte de variabilidade genética, a qual poderá influenciar o FR. Convém salientar a importância de serem avaliados o mecanismo de resistência e a herança da resistência ao glyphosate nos biótipos estudados neste trabalho, a fim de melhor entender o grau de variabilidade genética de cada biótipo em particular. Em segundo lugar, é possivel que a resistência nos diferentes biótipos coletados tenha sido originada de mais de uma mutação (ausência de efeito fundador), o que também contribui para a variabilidade genética elevada. Em terceiro lugar, os valores de FR também poderiam variar em função do estádio de desenvolvimento das plantas. No entanto, Koger et al. (2004) calcularam os FRs considerando diferentes estádios de desenvolvimento de biótipos de buva e detectaram apenas pequenas variações nos FRs. Em quarto lugar, os valores de FR para um mesmo biótipo podem variar conforme a variável avaliada, a exemplo do que aconteceu no presente experimento (Tabela 1), pois foram constatados alto e baixo niveis de resistência para um mesmo biótipo, em função da variável avaliada, confirmando os resultados de Moreira et al. (2007).

Em sintese, foi confirmada a hipótese de resistência ao glyphosate em todos os biótipos de Conyza spp. suspeitos, oriundos das regiões sudoeste e oeste do Paraná, que estiveram sob

Tabela 1 - Níveis de glyphosate necessários para produzir $50 \%$ de controle $\left(C_{50}\right)$ ou reduzir $50 \%$ a biomassa $\left(\mathrm{GR}_{50}\right)$ e fatores de resistência (FRs) dos biótipos de Conyza spp. avaliados

\begin{tabular}{|c|c|c|c|c|c|c|c|c|c|c|}
\hline \multirow[b]{2}{*}{ Biótipo } & \multicolumn{3}{|c|}{$\mathrm{C}_{5 \mathrm{O}} * *$} & \multicolumn{2}{|c|}{$\mathrm{GR}_{5 \mathrm{O}} * *$} & \multicolumn{5}{|c|}{$\mathrm{FR}^{* * *}$} \\
\hline & $\begin{array}{l}\text { Controle } \\
7 \text { DAA* }\end{array}$ & $\begin{array}{l}\text { Controle } \\
14 \text { DAA }\end{array}$ & $\begin{array}{l}\text { Controle } \\
21 \text { DAA }\end{array}$ & $\begin{array}{l}\text { Matéria } \\
\text { Verde }\end{array}$ & $\begin{array}{l}\text { Matéria } \\
\text { Seca }\end{array}$ & $\begin{array}{c}\text { Controle } \\
7 \text { DAA }\end{array}$ & $\begin{array}{l}\text { Controle } \\
14 \text { DAA }\end{array}$ & $\begin{array}{l}\text { Controle } \\
21 \text { DAA }\end{array}$ & $\begin{array}{l}\text { Matéria } \\
\text { Verde }\end{array}$ & $\begin{array}{c}\text { Matéria } \\
\text { Seca }\end{array}$ \\
\hline Corbélia & $524,5^{2 /}$ & $770,0^{2 / 1}$ & $796,0^{4 /}$ & $561^{\frac{1}{}}$ & $492^{2 !}$ & 3,54 & 5,69 & 6,42 & 6,44 & 4,96 \\
\hline Cascavel 3 & $1.391,2^{4 /}$ & $910,9^{4 /}$ & $703,5^{4^{\prime}}$ & $518^{2 /}$ & $1.230^{2 !}$ & 9,39 & 6,74 & 5,67 & 5,95 & 12,42 \\
\hline Florianópolis & $138,7^{2 /}$ & $186,6^{2 /}$ & $145,7^{2 /}$ & $125^{\frac{1 /}{}}$ & $198^{\frac{2}{1}}$ & 0,93 & 1,38 & 1,17 & 1,43 & 2,00 \\
\hline Cascavel 1 & $3.877,6^{2 /}$ & $1173,8^{2 /}$ & $968,6^{2 \prime}$ & $12^{\frac{1 /}{}}$ & $6^{1^{-}}$ & 26,19 & 8,68 & 7,81 & 0,13 & 0,06 \\
\hline Campo Bonito & $438,9^{2 /}$ & $352,8^{2 !}$ & $494,4^{2 /}$ & $364^{1 /}$ & $3.690^{2 !}$ & 2,96 & 2,61 & 3,98 & 4,18 & 37,27 \\
\hline Cascavel 2 & $2.094,4^{4 /}$ & $2.401,8^{4 /}$ & $1.979,4^{4 /}$ & $724^{1 /}$ & $1.363^{1^{1 /}}$ & 14,15 & 17,77 & 15,9 & 8,32 & 13,76 \\
\hline Três Barras 1 & $2.570,7^{4 /}$ & $1.927,0^{4 /}$ & $1.776,2^{4 /}$ & $518^{2 /}$ & $688^{-1 /}$ & 17,36 & 14,26 & 14,33 & 5,95 & 6,94 \\
\hline São Paulo & $209,9^{2 /}$ & $248,8^{2 /}$ & $170,1^{2 /}$ & $61^{\frac{2 /}{1}}$ & $7^{1 / /}$ & 1,41 & 1,84 & 1,37 & 0,70 & 0,07 \\
\hline Pato Branco & $148,0^{2 /}$ & $135,1^{2 /}$ & $124,0^{2 /}$ & $87^{2 /}$ & $99^{3 /}$ & 1,00 & 1,00 & 1,00 & 1,00 & 1,00 \\
\hline Capanema & $1.651,3^{4 /}$ & $1270,6^{4 /}$ & $1.152,0^{4 /}$ & $362^{2 /}$ & $781^{1 /}$ & 11,2 & 9,40 & 9,29 & 4,16 & 7,88 \\
\hline Três Barras 2 & $218,4^{2 /}$ & $191,0^{4 /}$ & $156,2^{2 !}$ & $598^{2 /}$ & $1.187^{2 !}$ & 1,47 & 1,41 & 1,26 & 6,87 & 11,98 \\
\hline Santa Izabel do Oeste & $984,2^{2 /}$ & $1064,2^{2-}$ & $1.776,2^{4-}$ & $598^{\frac{1}{}}$ & $976^{-/}$ & 6,64 & 7,87 & 14,33 & 6,87 & 9,85 \\
\hline
\end{tabular}


pressão de seleção pelo produto. Os valores de FR atingiram grande amplitude entre os biótipos suspeitos, indicando a existência de ampla variabilidade quanto a essa característica. Os FRs variaram conforme a determinação efetuada, atingindo valores máximos superiores aos constatados em outros trabalhos que investigaram biótipos de Conyza spp. resistentes ao glyphosate no Brasil e no exterior. Essas informações são importantes, pois poderão servir de base para determinar ações de manejo diferenciadas nas áreas onde já há o problema e para prevenir a ocorrência de novas áreas com buva resistente ao glyphosate.

\section{AGRADECIMENTOS}

Ao Conselho Nacional de Desenvolvimento Científico e Tecnológico (CNPq), pelo suporte financeiro e concessão de bolsas de iniciação científica e de produtividade. Ao DIRPPG/ UTFPR, pelo apoio à publicação.

\section{LITERATURA CITADA}

BHERING, S. B. et al. Mapa de solos do Estado do Paraná: legenda atualizada. Rio de Janeiro: Embrapa/IAPAR, 2008. $74 \mathrm{p}$.

DAVIS, V. M.; GIBSON, K. D.; JOHNSON, W. G. A field survey to determine distribution and frequency of glyphosate-resistant horseweed (Conyza canadensis) in Indiana. Weed Technol., v. 22, n. 2, p. 331-338, 2008.

FRANS, R. et al. Experimental design and techniques for measuring plant responses to weed control practices. In: CAMPER, N. D. Research methods in weed science. 3.ed. Champaign: Southern Weed Science Society, 1986. p. 29-46.

GAZZIERO, D. et al. Critérios para Relatos Oficiais Estatísticos de Biótipos de Plantas Daninhas Resistentes a Herbicidas. Sete Lagoas: Sociedade Brasileira da Ciência das Plantas Daninhas/Campinas: Associação Brasileira de Ação à Resistência de Plantas aos Herbicidas no Brasil, 2008.

HALFHILL, M. D. et al. Transformation and segregation of GFP fluorescence and glyphosate resistance in horseweed (Conyza canadensis) hybrids. Plant Cell Rep., v. 26, n. 3, p. 303-311, 2007.

HEAP, I. International survey of resistant weeds. Disponível em: $<$ http://www.weedscience.org $>$. Acesso em: 30 nov. 2011

KOGER, C. H. et al. Glyphosate-resistant horseweed (Conyza canadensis) in Mississippi. Weed Technol., v. 18, n. 3, p. 820-825, 2004.
LAMEGO, F. P.; VIDAL, R. A. Resistência ao glyphosate em biótipos de Conyza bonariensis e Conyza canadensis no Estado do Rio Grande do Sul, Brasil. Planta Daninha, v. 26, n. 2 , p. $467-471,2008$.

MOREIRA, M. S. et al. Resistência de Conyza canadensis e C. bonariensis ao herbicida ghyphosate. Planta Daninha, v. 25 , n. 1, p. $157-164,2007$

MAIN, C. L. et al. Response of selected horseweed (Conyza canadensis (L.) Cronq.) populations to glyphosate. J. Agric. Food Chem., v. 52, n. 4, p. 879-883, 2004.

PRATLEY, J. et al. Glyphosate resistance in annual ryegrass. In: ANNUAL CONFERENCE OF THE GRASSLAND SOCIETY OF NEW SOUTHWALES, 11., 1996, Wagga Wagga. Proceedings... WaggaWagga: The Grassland Society of New South Wales, 1996. p. 126.

RYAN, G.F. Resistance of common groundsel to simazine and atrazine. Weed Sci., v. 18, n. 5, p. 614-616, 1970.

SEEFELDT, S. S.; JENSEN, J. E.; FUERST, E. P. Log logistic analysis of herbicide dose-response relationships. Weed Technol., v. 9, n. 2, p. 218-227, 1995.

SHRESTHA, A. et al. Growth stage influences level of resistance in glyphosate-resistant horseweed. California Agric., v. 61, n. 2, p. 67-70, 2007

THEBAUD, C.; ABBOTT, R. J. Characterizations of invasive Conyza species (Asteraceae) in Europe: quantitative trait and isozyme analysis. Am. J. Bot., v. 82, n. 3, p. 360368, 1995.

VARGAS, L. et al. Alteração das características biológicas dos biótipos de azevém (Lolium multiflorum) ocasionada pela resistência ao herbicida glyphosate. Planta Daninha, v. 23, n. 1, p. 153-160, 2005.

VARGAS, L. et al. Buva (Conyza bonariensis) resistente ao glyphosate na região Sul do Brasil. Planta Daninha, v. 25, n. 3, p. 573-578, 2007.

VANGESSEL, M. J. Glyphosate resistant horseweed from Delaware. Weed Sci., v. 49, n. 6, p. 703-705, 2001.

VANGESSEL, M. J. et al. Influence of glyphosate-resistant horseweed (Conyza canadensis) growth stage on response to glyphosate applications. Weed Technol., v. 23, n. 1, p. 49$53,2009$.

VIDAL, R. A. et al. Glyphosate resistant biotypes of wild poinsettia (Euphorbia heterophylla L.) and its risk analysis on glyphosate-tolerant soybeans. J. Food Agric. Environ., v. 5, n. 2, p. 265-269, 2007a.

VIDAL, R. A.; TREZZI, M.; LOUX, M. Definindo resistência aos herbicidas. R. Plantio Direto, v. 100, n. 4, p. $18-19,2007 b$ 